\title{
A Sintaxe do espanhol e do português brasileiro: evidências para a gramática não nativa do espanhol
}

Adriana Martins Simões

\author{
Mestre e doutoranda em \\ Letras pelo Programa de Pós- \\ Graduação em Língua Espanhola \\ e Literaturas Espanhola e \\ Hispano-Americana da Faculdade \\ de Filosofia, Letras e Ciências \\ Humanas da Universidade de \\ São Paulo. Bolsista de doutorado \\ do CNPq. \\ Contato: adrimsimoes@usp.br
}


CARACOL 4 / DOSSIÊ

PALAVRAS-CHAVE

espanhol; português brasileiro

objeto pronominal acusativo;

gramática não nativa;

aquisição/aprendizagem de LE

KEYWORDS

Spanish; Brazilian Portuguese; accusative pronominal object; non-native grammar; foreign

language acquisition/learning
Resumo

Este trabalho apresenta indícios sobre a gramática não nativa do espanhol (Simões, 2010). Tendo em vista as diferenças sintáticas entre a gramática do espanhol e do português brasileiro (González, 1994, 1998, 1999, 2001, 2003, 2005, 2008), decorrentes da mudança linguística ocorrida no século XIX nesta última (Cyrino, 1993; Duarte, 1989; Galves, 2001; Kato, 1993; Tarallo, 1993), investigamos a aquisição/aprendizagem da gramática não nativa do espanhol, tendo como fundamentação teórica o modelo gerativista de aquisição de línguas estrangeiras (González, 1994, 1998, 1999, 2001, 2003, 2005; Liceras, 1996, 1997, 2002, 2003). Os dados revelaram que a coexistência de gramáticas do português brasileiro se reflete na gramática não nativa, bem como encontramos indícios de reestruturação e dos elementos que poderiam desencadeá-la.

Contudo, a representação mental dos aprendizes não corresponderia à dos falantes nativos e o processo de reestruturação seria apenas parcial. Encontramos evidências sobre a natureza da gramática não nativa e da permeabilidade.

\section{AbStRact}

This paper presents evidences on Spanish non-native grammar (Simões, 2010). Considering the syntactic differences between Spanish and Brazilian Portuguese 
A SINTAXE DO ESPANHOL E DO PORTUGUÊS BRASILEIRO ADRIANA MARTINS SIMÕES

grammar (González, 1994, 1998, 1999, 2001,

$2003,2005,2008)$, by virtue of linguistics

changes which started to occur in the $19^{\text {th }}$

century in the latter (Cyrino, 1993; Duarte, 1989;

Galves, 2001; Kato, 1993; Tarallo, 1993), it was

carried out a study about Spanish non-native

grammar acquisition, based on generative

approach to foreign language acquisition

(González, 1994, 1998, 1999, 2001, 2003,

2005; Liceras, 1996, 1997, 2002, 2003). The

data showed that the coexistence of Brazilian

Portuguese grammars reflects on non-native

grammar, as well as there are evidences on

restructuring and elements which could trigger

it. However, the learner's mental representation

would not correspond to a native speaker's

one and the restructuring process would only

be partial. Our findings reveal evidences about

non-native grammar and permeability nature. 


\section{o. Introdução}

Abordaremos neste trabalho aspectos da sintaxe do espanhol e do português brasileiro (doravante PB) relacionadas ao objeto pronominal acusativo, que constituíram evidências a respeito da gramática não nativa do espanhol. Esses resultados são provenientes da pesquisa de mestrado ${ }^{\mathrm{I}}$ que desenvolvemos, cujo objetivo foi investigar a aquisição/aprendizagem da gramática não nativa do espanhol de aprendizes brasileiros de diferentes gerações. González (I994, I998, I999, 2001, 2003, 2005, 2008) constatou que o espanhol e o PB são línguas que apresentam diferenças sintáticas na área da gramática que focalizamos, como também na colocação pronominal, denominadas pela autora como inversamente assimétricas. Essas diferenças se originaram do processo de mudança linguística iniciada no PB no século XIX (Cyrino, I993; Duarte, I989; Galves, 200I; Kato, I993; Tarallo, I993). Por outro lado, essas duas línguas mantêm algumas semelhanças sintáticas que são decorrentes da incorporação de resíduos da mudança linguística ao PB por intermédio da aprendizagem escolar, o que se configura como a gramática do PB aprendido. Considerando-se essas questões sobre a gramática do espanhol e do PB e tendo a hipótese ${ }^{2}$ de que a gramática não nativa dos aprendizes brasileiros mais jovens seria mais permeável à gramática adquirida do $\mathrm{PB}^{3}$, nossa pesquisa foi conduzida com vistas a encontrar respostas para os seguintes questionamentos:

I Realizamos nossa pesquisa de mestrado sob a orientação da Profa. Dra. Neide Therezinha Maia González. Na época contamos com uma bolsa da CAPES para a realização da pesquisa.

2 A hipótese que seguimos nessa investigação teve origem nos resultados obtidos em nossa pesquisa de TGI (Trabalho de Graduação Interdisciplinar), que desenvolvemos na graduação (Simões, 2006). Nesse trabalho, observamos uma diferença na produção não nativa de aprendizes mais jovens em comparação à de aprendizes de gerações anteriores em relação ao preenchimento do objeto direto pronominal de $3^{\text {a }}$ pessoa, o que nos levou a aprofundar essa questão.

3 Referir-nos-emos em alguns momentos a duas gramáticas do PB, a gramática adquirida e a gramática aprendida, termos que serão especificados mais adiante. 
A SINTAXE DO ESPANHOL E DO PORTUGUÊS BRASILEIRO

ADRIANA MARTINS SIMÕES

I. Tendo em vista que na mente/cérebro dos falantes nativos do PB podem coexistir duas gramáticas para a LM, qual seria a tendência de aceitabilidade do objeto pronominal acusativo de $3^{\mathrm{a}}$ pessoa na gramática não nativa do espanhol dos aprendizes brasileiros de diferentes faixas etárias?

2. No caso de detectarmos a atuação da gramática do espanhol na gramática não nativa, como delimitaríamos o que de fato seria o reflexo da gramática do espanhol e o que seria o reflexo da gramática da LM aprendida ou adquirida?

3. Se o maior ou menor índice de aceitabilidade do clítico e do pronome tônico estiver determinado pela faixa etária do aprendiz, que função desempenharia a aprendizagem do português na escola na gramática não nativa e qual a relação disso com o nível e a "qualidade" de instrução dos estudantes?

4. Entre os estudantes de menor faixa etária, que pressupomos serem mais permeáveis à gramática atual do $\mathrm{PB}$, o aumento de horas de instrução formal e a maior exposição ao input do espanhol os levariam à reestruturação da gramática não nativa?

5. Qual a relação entre essa coexistência de gramáticas no PB e sua proporção na competência linguística dos brasileiros de diferentes faixas etárias com a gramática não nativa do espanhol no que se refere a esse ponto em que as gramáticas das duas línguas se tornam inversamente assimétricas?

Analisamos os dados da gramática não nativa do espanhol à luz da teoria gerativista de aquisição/aprendizagem de língua estrangeira (LE) (González, 1994, 1998, 1999, 2001, 2003, 2005; Liceras, 1996, 1997, 2002, 2003) e das questões referentes à mudança linguística na proposta desenvolvida por 
CARACOL 4 / DOSSIÊ

Lightfoot (2006). Além disso, tanto as gramáticas do espanhol e do PB quanto a gramática não nativa foram vistas a partir da perspectiva biológica de língua (Chomsky, I98I, I986) aliada à perspectiva social (Labov, 2008; Weinreich, Labov, Herzog, 2006).

$\mathrm{Na}$ primeira parte do artigo apresentaremos os conceitos de língua e gramática em que nos baseamos. A seguir, serão expostos aspectos relativos à sintaxe do espanhol e do PB, bem como o estatuto de suas gramáticas. Nas duas partes subsequentes estarão a metodologia utilizada e o referencial teórico. A quinta parte será dedicada à exposição e discussão dos resultados sobre a gramática não nativa do espanhol e por fim teremos as considerações finais.

\section{OS CONCEITOS DE LÍNGUA E GRAMÁTICA}

Em nossa pesquisa consideramos língua e gramática como uma entidade biológica presente na mente/cérebro de todos os seres humanos, conforme Chomsky (I98I, I986). De acordo com esse autor, haveria uma capacidade linguística inata denominada de Faculdade da Linguagem (FL). A Gramática Universal (GU) constituiria o estado inicial da FL e a língua-I o seu estado final após o processo de aquisição.

A aquisição de uma dada língua ocorreria pela interação entre a GU e os dados do ambiente linguístico, que levariam à fixação de parâmetros e à emergência de uma língua-I. A língua-I, enquanto internalizada, intensional e individual, se opõe à língua-E, enquanto externa e extensional. Enquanto a língua-I se vincula ao conhecimento que o falante tem da sua língua, à sua competência linguística, a língua-E se vincula ao desempenho linguístico, ao uso que o indivíduo faz a partir do conhecimento da língua. 
A SINTAXE DO ESPANHOL E DO PORTUGUÊS BRASILEIRO

ADRIANA MARTINS SIMÕES

Com a fixação dos parâmetros correspondentes à sua língua materna (LM), o falante teria representada em sua mente/cérebro uma gramática nuclear. Além disso, ao longo da vida, fenômenos decorrentes de mudança linguística, empréstimos de outras línguas, entre outros, seriam incorporados à periferia marcada, que abriga fenômenos que não constituem fixação paramétrica. Tanto a gramática nuclear como a periferia marcada integrariam a língua-I.

Além da perspectiva biológica, consideramos também em nossa pesquisa a perspectiva social de língua (Labov, 2008; Weinreich, Labov, Herzog, 2006)4. Segundo Labov (2008), os sistemas linguísticos teriam um caráter heterogêneo na medida em que as línguas sofreriam variação ao estarem inseridas em ambientes sociais, as comunidades de fala. O processo de variação nas línguas estaria sujeito a regras linguísticas inerentes ao sistema e a regras sociais, bem como poderia ou não desencadear mudança linguística.

Tendo em vista que investigamos uma área da sintaxe do espanhol e do PB que apresenta variação e mudança linguística nesta última, uma das gramáticas do $\mathrm{PB}$ corresponderia à gramática adquirida e estaria incorporada à gramática nuclear da língua-I. Já a outra gramática do PB seria produto de aprendizagem formal e corresponderia à periferia marcada, como veremos a seguir. A teoria sociolinguística seria inserida em nossa pesquisa nesse âmbito da variação no PB e sua relação com os fatores sociais faixa etária e nível

4 A conjugação da teoria sociolinguística à gerativa se justifica devido às características de nosso objeto de estudo: por um lado temos as gramáticas do espanhol e do PB e nesta última, resíduos de mudança linguística, que se configuram como aprendizagem formal, como veremos mais adiante; por outro lado, lidamos com a gramática não nativa do espanhol, que também se relaciona à aprendizagem formal. A atuação da aprendizagem formal do PB na aquisição/aprendizagem do espanhol por falantes brasileiros mostrou-se relevante na pesquisa de Yokota (2007) e em nossa pesquisa anterior (Simões, 2006). Além disso, a conjugação dessas duas teorias foi realizada por pesquisadores como Kato \& Tarallo (I986) com resultados significativos a respeito do PB. 
CARACOL 4 / DOSSIÊ

de escolaridade, que analisamos em nossos dados, bem como no âmbito da aquisição/aprendizagem do espanhol, que também se vincula a aspectos sociais.

\section{A SinTAXE DO ESPANHOL E DO PB}

Diversas pesquisas constataram que a partir do século XIX o PB começou a apresentar, entre outros fenômenos, a perda do clítico acusativo de $3^{\mathrm{a}}$ pessoa o(s), $\mathrm{a}(\mathrm{s})$, a ampliação da possibilidade de objetos nulos e o surgimento do pronome lexical ele(s), elas(s) em função acusativa, bem como alterações na colocação pronominal (cf. Cyrino, I993, I996; Duarte, I989; Galves, I993, 200I; Kato, I993; Tarallo, I993; entre outros). Conforme Galves (I993), os fenômenos constatados no PB indicariam não apenas uma mudança quantitativa no interior de uma mesma gramática, mas uma mudança qualitativa de gramática no PB, diferenciando-a da gramática do português europeu.

González (I994, I998, 1999, 2001, 2003, 2005, 2008) observou que devido a essas mudanças na gramática do $\mathrm{PB}$, haveria diferenças entre a gramática do espanhol e a dessa língua em diferentes estruturas sintáticas5, entre elas a realização do objeto pronominal. Assim, a autora se refere a essas diferenças como uma inversa assimetria, na medida em que o espanhol apresenta uma tendência à realização pronominal e esta se dá por pronome átono e o PB uma

5 As outras estruturas sintáticas que apresentam diferenças entre o espanhol e o PB investigadas por González (I994, I998, I999, 200I, 2003, 2005, 2008) foram a expressão do sujeito e objeto indireto pronominal, as construções reflexivas e pronominais, as construções com dativo, as construções passivas e impessoais e a colocação pronominal. Todas essas estruturas se relacionam ao processo de mudança linguística que ocorreu no PB e foram analisadas por González tanto do ponto de vista contrastivo quanto da interlíngua. 
A SINTAXE DO ESPANHOL E DO PORTUGUÊS BRASILEIRO

ADRIANA MARTINS SIMÕES

tendência à não realização pronominal ou à realização por pronome lexical.

Observem-se as sentenças a seguir que evidenciam essa assimetria:

(I) Vi ele ontem na rua.

(2) Lo vi a él ayer en la calle (no a ella).

(3) Lo vi ayer en la calle.

(4) *Vi [a] él ayer en la calle.

(5) A Joana viu $\varnothing$ na televisão ontem.

(6) *Juana $\varnothing$ vio en la televisión ayer.

(7) Juana lo vio en la televisión ayer.

Devido ao processo de mudança linguística, o clítico acusativo de $3^{\mathrm{a}}$ pessoa já não faria parte da gramática adquirida naturalmente no PB contemporâneo, uma vez que não aparece na fala de crianças adquirindo essa língua ${ }^{6}$ (Magalhães, 2006). Apesar de ter sido extinto da aquisição natural, esse clítico permanece ainda na produção, sobretudo escrita, de brasileiros escolarizados, conforme atestaram alguns estudos7 (Correa 1990, apud Nunes 1993; Duarte, I989). Assim, a permanência desse clítico na gramática do PB seria produto de

6 Os dados da pesquisa de Magalhães (2006) revelaram que as crianças adquirindo o PB tendem a realizar mais objetos nulos do que as que estão adquirindo o português europeu, bem como apresentam o pronome lexical, enquanto as crianças portuguesas apresentam clíticos de $3^{\mathrm{a}}$ pessoa. Esses resultados revelam que as tendências que estão previstas no sistema adulto das respectivas línguas aparecem desde o início da aquisição.

7 Os resultados da pesquisa de Duarte (I989) apresentaram ausência de clítico na fala de jovens e de pessoas correspondentes à maior faixa etária e com apenas o $\mathrm{I}^{\mathrm{o}}$ grau, assim como houve um leve aumento em sua produção conforme se eleva a escolaridade. Já os dados de Correa (I990, apud Nunes, I993) revelaram que os clíticos aparecem primeiro na escrita e apenas começam a aparecer na fala após alguns anos de escolaridade, bem como tornam-se mais frequentes à medida que aumenta o nível de instrução, em especial na escrita. 
instrução formal, de modo que Galves (200I) e Kato (2005) propõem que esses pronomes integrariam a periferia marcada. Quanto ao espanhol, ao contrário do PB, o clítico é adquirido naturalmente, incorporando-se à gramática nuclear da língua-I, dado que é produzido inclusive por falantes nativos de espanhol sem escolaridade (Fanjul, I999). Com base no exposto, vemos que as sentenças (8) e (9) a seguir, embora aparentem ser idênticas, implicariam diferentes representações nas respectivas gramáticas, representações essas que não estão relacionadas apenas ao ponto de vista paramétrico, mas também ao estatuto desse clítico na mente/cérebro dos falantes nativos.

(8) Juan lo vio ayer.

(9) O João o viu ontem.

Com relação ao objeto nulo, conforme Campos (i986) e Fernández Soriano (I999), o espanhol seria uma língua em que essa categoria vazia seria possível apenas em referência a antecedente [-específico; -definido] ${ }^{8}$, com exceção de algumas variedades em que o objeto nulo ocorreria em contextos mais amplos ${ }^{9}$ (cf. Fernández Ordóñez, I999). Em contrapartida, o PB seria uma língua em que o objeto nulo seria possível não apenas com antecedente [-animado; -específico], como também em contexto de antecedente [+animado; -específico], [-animado; +específico] (cf. Cyrino, I996) e inclusive [+animado; +específico].

8 Conforme Laca (I999), o espanhol seria uma língua em que os substantivos comuns não constituiriam expressões referenciais na ausência de determinante. Assim, dado que o clítico acusativo seria um pronome definido, seria incompatível que retomasse um elemento sem valor referencial (cf. Di Tullio, I997).

9 Entre essas variedades abordadas em Fernández Ordóñez (I999), destacamos o espanhol falado na Serra do Equador e no Paraguai, em que o objeto nulo poderia ocorrer com antecedente [-animado; +determinado] em diferentes estruturas sentenciais. 
A SINTAXE DO ESPANHOL E DO PORTUGUÊS BRASILEIRO

ADRIANA MARTINS SIMÕES

As diferenças entre o espanhol e o PB no âmbito do objeto nulo poderiam não restringir-se aos traços semânticos do antecedente, mas estarem relacionadas também à natureza da categoria vazia do objeto nulo. Assim, na literatura gerativista, o objeto nulo do espanhol foi analisado como uma variável (Campos, I986) e também poderia ser um pro (Demonte, I994), enquanto no PB seria um pro (Galves, 200I) ou poderia comportar-se como um epíteto (Kato, 2002). As sentenças abaixo evidenciam as diferenças de gramaticalidade entre as duas línguas em relação aos traços semânticos do antecedente.

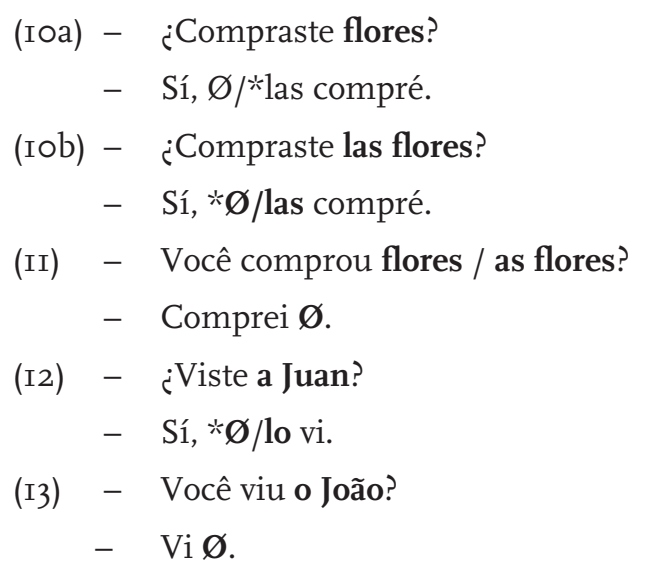

Quanto ao pronome lexical, o espanhol permite que esse pronome ocorra em função acusativa apenas em casos em que é correferente com o clítico e haja a necessidade de estabelecer contraste entre diferentes referentes, bem como se restringe a antecedente [+humano] (Groppi, I997). Por outro lado, no PB o pronome lexical teria perdido a restrição a antecedente [+humano] e seria considerado um pronome fraco (Kato, 2002) em oposição a esse pronome do espanhol, que seria forte. Observem-se as sentenças (I4)-(I6), que ilustram essas diferenças. 
(I4) *Vi él.

(I5) Lo vi a él.

(I6) Eu vi ele.

No que tange à colocação pronominal, nas locuções verbais o clítico ocorre como próclise ao auxiliar no espanhol, enquanto no PB essa colocação do clítico já não seria possível devido à mudança linguística, que levou o PB a permitir a próclise ao principal (Cyrino, I993; Pagotto, I993), que é agramatical em espanhol. Por outro lado, quando se trata do clítico acusativo de $3^{\mathrm{a}}$ pessoa, ainda é possível a próclise ao auxiliar no PB. Portanto, assim como esse clítico se manteve no PB por intermédio da aprendizagem escolar, a manutenção dessa sua forma de colocação nas locuções verbais tem a mesma origem ${ }^{\mathrm{I}}$. Observem-se as sentenças a seguir, que ilustram essas diferenças entre as duas línguas:

(I7) Juan me había dicho que venía hoy.

(I8) *Juan había me dicho que venía hoy.

(I9) *João me tinha dito que vinha hoje.

(20) João tinha me dito que vinha hoje.

(2I) Ele o tinha visto de manhã.

(22) Ele tinha o visto de manhã.

IO Kato (2005) propõe que, a pesar de a instrução formal recuperar o clítico e sua colocação como próclise ao auxiliar, o conhecimento linguístico que a escola recupera seria parcial por não desencadear a aquisição simultânea das áreas sintáticas relacionadas, assim como esse conhecimento não equivaleria ao do falante de português do século XVIII, que era adquirido de forma natural. 
A SINTAXE DO ESPANHOL E DO PORTUGUÊS BRASILEIRO

ADRIANA MARTINS SIMÕES

Com base no exposto, vimos que quando as gramáticas do espanhol e do PB apresentam aspectos que diferenciam sua sintaxe, a inversa assimetria, nos termos de González (1994, I998, I999, 2001, 2003, 2005, 2008), temos o objeto nulo, o pronome lexical e a próclise ao principal, que correspondem à aquisição natural e, portanto, compõem a gramática adquirida do PB. Por outro lado, quando se trata do clítico acusativo de $3^{\mathrm{a}}$ pessoa e de sua colocação como próclise ao auxiliar, vemos que há uma aproximação entre as gramáticas das duas línguas. Nesse caso, temos estruturas oriundas de resíduos de mudança linguística no PB, que se mantêm na língua por integrarem a periferia marcada, constituindo, portanto, a gramática aprendida dessa língua.

\section{A METOdologia dA PESQUISA}

Com o objetivo de que a intuição na gramática do espanhol ${ }^{\text {II }}$ comparada à intuição nas gramáticas do $\mathrm{PB}^{12}$ pudesse fornecer pistas a respeito da gramática não nativa dos aprendizes, elaboramos testes de aceitabilidade a fim de captar a intuição em ambas as línguas. Aliamos a isso os fatores sociais faixa etária, nível de instrução em LM e nível de aprendizagem do espanhol como LE no intuito de que essas variáveis pudessem também oferecer evidências.

II Veremos na parte dedicada ao referencial teórico que Liceras $(1996,33)$ propõe que na aquisição de LE haveria um acesso indireto à GU a partir da LI ou de outras línguas adquiridas. A aquisição de LE ocorreria a partir de procedimentos secundários de domínio específico, que pressupõem que o aprendiz tenha intuições sobre a língua que está adquirindo. Assumimos, portanto, que haveria intuição na aquisição/aprendizagem de LE, ainda que esta não seja como a intuição de um falante nativo, como propõe Chomsky (I98I).

I2 Quanto às gramáticas do PB, a gramática adquirida seria a que se configura como intuição, conforme Chomsky (I98I). Entretanto, como veremos na parte da análise, encontramos evidências de que a gramática não nativa do espanhol teria o mesmo estatuto da gramática aprendida do PB. Assim, seguindo esse raciocínio, propomos que haveria também intuição na gramática aprendida do PB, que se assemelharia à intuição não nativa. 
CARACOL 4 / DOSSIÊ

Como variáveis dependentes, analisamos as formas de realização do objeto pronominal acusativo de $3^{\text {a }}$ pessoa em diferentes contextos estruturais e em referência a antecedentes com diferentes traços semânticos, bem como analisamos as formas de colocação pronominal em locuções verbais com os pronomes de $\mathrm{I}^{\mathrm{a}}$ e $3^{\mathrm{a}}$ pessoa. Quanto às variáveis independentes, aplicamos os testes a informantes de diferentes faixas etárias, sendo eles aprendizes de espanhol entre i2 e i8 anos, que compreendem a faixa etária I (FEI), e aprendizes acima de 50 anos, que compreendem a faixa etária 2 (FE2). Esses informantes possuíam ou estavam cursando o Ensino Fundamental, o Ensino Médio ou o Ensino Superior e estavam distribuídos em diferentes níveis de aprendizagem de espanhol como LE³, sendo nível básico (I00-I20 horas/aula), intermediário (I75-280 horas/aula) e avançado (315-430 horas/aula).

Os dados foram analisados de forma quantitativa por meio do programa estatístico Package for the Social Sciences, SPSS, versão I5.0 para Windows. Como as quantidades de informantes variavam em cada um dos fatores analisados, extraímos a média de aceitabilidade da ocorrência das variáveis dependentes.

\section{O REFERENCIAL TEÓRICO}

\subsection{A aquisição/aprendizagem de LE}

Fundamentamos a análise da gramática não nativa na teoria gerativista de aquisição/aprendizagem de LE (González, I994, I998, I999, 2001, 2003, 2005; Liceras, I996, 1997, 2002, 2003). Adotamos a vertente da teoria que

I3 Os informantes que responderam aos testes pertenciam a três diferentes instituições. Os cursos oferecidos por essas instituições se enquadram como cursos livres de línguas estrangeiras. 
A SINTAXE DO ESPANHOL E DO PORTUGUÊS BRASILEIRO

ADRIANA MARTINS SIMÕES

atribui um papel importante à LM no processo de aquisição, na medida em que esta mediaria o contato do input com a GU, à qual os aprendizes de LE teriam acesso de forma indireta.

4.1.1. González (1994, 1998, 1999, 2001, 2003, 2005)

González (1994, 1998, I999, 2001, 2003, 2005), apoiando-se em estudos anteriores, inseriu o fenômeno da transferência no modelo cognitivo gerativista. Conforme a autora, a transferência seria $\operatorname{cognitiva~}^{\mathrm{I} 4} \mathrm{e}$ atuaria no nível do intake determinando a seleção e o processamento do input. O intake seria afetado por fatores cognitivos, como o conhecimento linguístico prévio e aspectos da GU.

A partir de dados de produção não nativa em espanhol, González (I994) constatou que em um primeiro momento a produção dos aprendizes apresentava tendências que a aproximavam da gramática da LM. González propõe que se trata de uma transferência, que corresponde, como vimos, a uma filtragem e processamento do input da LE, que aproxima a gramática da língua alvo da gramática da LM e gera aproximações equivocadas da L2.

Além da transferência, a autora detectou a estratégia de generalização livre, denominada por ela de transferência às avessas. González constatou que na aquisição/aprendizagem do espanhol pelos aprendizes brasileiros ocorrem usos inadequados do clítico. Um desses fenômenos seria a supergeneralização de regras, que consiste na generalização de uma regra da gramática do espanhol

I4 O fenômeno de transferência proposto por González (I994, I998, I999, 2001, 2005) difere do proposto pela Análise Contrastiva de base behaviorista, em que transferência era vista como a manutenção de hábitos da Li na LE. 
CARACOL 4 / DOSSIÊ

e se manifesta no uso de um clítico na duplicação de um complemento ${ }^{15}$. O outro fenômeno seria a distorção de regras, que compreende os casos em que não é possível recuperar a referência do clítico ${ }^{\mathrm{T}}$.

Conforme a autora, esses fenômenos constituem uma tentativa do aprendiz de aproximar-se da gramática do espanhol, mas que acabariam distanciando-o tanto da LE quanto de sua LM. Esses fenômenos ocorreriam em decorrência da instrução formal em LE, que levaria os aprendizes a focalizarem os clíticos presentes no input do espanhol apenas em seu efeito sonoro, sem, contudo, levá-los à percepção de sua função e referência na oração. A hipótese de González é de que, apesar de produzir clíticos, o aprendiz não assimila as regras subjacentes da gramática da LE, o que revela que aprendizagem não significa aquisição.

Além disso, González observou que as construções que analisou estavam correlacionadas e provocavam um efeito em cadeia na gramática da interlíngua dos aprendizes. Assim, a produção desses aprendizes apresentava as tendências da gramática do $\mathrm{PB}$, tendências essas, que, como vimos, estão em processo de variação e mudança linguística e se originaram de um ponto comum na gramática.

Nosso trabalho se originou dessa pesquisa de González e entre os resultados que ela encontrou nos interessam particularmente o fenômeno de generalização de regras, no sentido de que a aprendizagem poderia não

I5 Um exemplo desse fenômeno seria a sentença (23). Nesse caso, apesar de ser um uso indevido do clítico, seria recuperada tanto sua referência quanto seu papel temático.

(23) Ayer me lo dijiste que no estabas de acuerdo... (...me dijiste que...).

I6 A sentença (24) ilustra esse fenômeno. Como não haveria uma função para esse clítico na sentença, também não haveria um referente e papel temático.

(24) Él dijo que me llamaba, peo aunque me lo llame no voy. (...aunque me llame..., uma vez que não há objeto direto que possa ser reproduzido anaforicamente pelo clítico lo.) 
A SINTAXE DO ESPANHOL E DO PORTUGUÊS BRASILEIRO

ADRIANA MARTINS SIMÕES

constituir aquisição, e o efeito em cadeia das construções relacionadas a um determinado parâmetro.

\subsubsection{Liceras (1996, 1997, 2002, 2003)}

Liceras (1996, 1997, 2002, 2003) propõe que o processo de aquisição de uma LE seria diferente do de aquisição da LM. Isso ocorreria em decorrência de que na aquisição de LM os dados linguísticos entram em contato com a GU e fazem com que emerja a gramática da língua correspondente aos dados mediante a fixação de parâmetros. Essa aquisição se daria a partir do nível prosódico e fonológico da língua ${ }^{\mathrm{r}}$, o que a autora denomina de procedimento bottom-up. No caso na aquisição da LE, os dados linguísticos já não levariam à (re)fixação dos parâmetros, devido ao fato de que os aprendizes de LE já teriam uma GU madura e o nível prosódico e fonológico sofisticado, o que faria com que não fossem sensíveis aos elementos abstratos que desencadeiam a fixação de parâmetros. Assim, esses aprendizes se utilizariam do procedimento topdown, o que significa que o acesso à LE ocorreria pelas estruturas sintáticas ${ }^{18}$ dessa língua.

I7 Ao longo do primeiro ano de vida a capacidade perceptiva das crianças passaria por mudanças (cf. Werker \& Tees, I999). Nazzi, Bertoncini e Mehler (I998) observaram que crianças aos quatro dias de vida foram capazes de distinguir o inglês do japonês, línguas que possuem propriedades rítmicas diferentes, mas não distinguiram o inglês do alemão, cujas propriedades rítmicas são semelhantes. Em contrapartida, Bosch \& Sebastian-Galles (I997, apud Werker \& Tees, I999) mostraram que crianças aos quatro meses são capazes de distinguir o catalão do espanhol. Esses resultados revelam a fixação paramétrica dos padrões rítmicos da LM e o início da aquisição da linguagem pela prosódia e a fonologia.

I8 Em uma pesquisa sobre a aquisição do espanhol como LI e L2 em contexto natural (Liceras, 2002 e 2003), observou-se que apenas as crianças adquirindo o espanhol como Li produziram monossylabic place holders, que constituem vogais que marcam a posição sintática do determinante e ativam o traço [+marcador de palavra/gênero] dos determinantes do espanhol. Esse resultado seria decorrente 
CARACOL 4 / DOSSIÊ

De acordo com Liceras, o processo de aquisição de uma LE não se configuraria como o crescimento de uma gramática como no caso da LM, mas como um processo de reestruturação da gramática não nativa. Esse processo, também denominado pela autora de tinkering ou bricolage, consiste na realização de reestruturações locais em porções isoladas da língua, tendo como base os padrões da LM e estruturas visíveis da língua alvo. Desse modo, ao contrário da LM, na LE as construções relacionadas a um único parâmetro seriam adquiridas de forma isolada, construção por construção ${ }^{\mathrm{I}}$.

Todas essas questões fariam com que a gramática não nativa não apresente uma representação mental igual à de um falante nativo. Por outro lado, Liceras (I996) defende que, assim como na gramática da LM, o aprendiz de LE também teria intuições sobre a gramática da língua alvo, por meio do confronto dos dados dessa língua e de procedimentos secundários de domínio específico. Assim como Liceras, propomos que o processo de aquisição de LE difere do de aquisição de LM e objetivamos encontrar evidências a respeito em nossos dados.

\subsection{A mudança linguística}

De acordo com a teoria de mudança linguística proposta pelo gerativista Lightfoot (2006), enquanto a língua-I de determinado indivíduo é estável, sua língua-E está em constante fluxo e apresenta instabilidade. As mudanças

da pouca sofisticação fonológica dessas crianças, que adquirem a sintaxe pela prosódia e fonologia Quanto às crianças que estavam adquirindo o espanhol como L2, propõe-se que sua aquisição da sintaxe seria a partir de elementos mais elaborados.

I9 A forma e o resultado do fenômeno de reestruturação proposto por Liceras (I996, I997, 2002, 2003) se assemelham e poderiam equivaler à proposta de Kato (2005) no que se refere à recuperação das perdas linguísticas oriundas de mudança linguística pela instrução escolar. 
A SINTAXE DO ESPANHOL E DO PORTUGUÊS BRASILEIRO

ADRIANA MARTINS SIMÕES

que ocorrem na língua-E de um indivíduo não promovem alterações em sua língua-I, mas poderiam desencadear mudanças na língua-I da próxima geração de falantes. A língua-I, por sua vez, promove mudanças na língua-E, já que, conforme o autor, a língua-E constitui o output da gramática.

Assim, para Lightfoot, a mudança linguística seria desencadeada a partir da interação entre a língua-I e a língua-E e ocorre, portanto, no âmbito da aquisição e da variação linguística. Entretanto, enquanto a mudança na língua-E é gradual, espalhando-se de forma lenta pelo espaço geográfico e social, a mudança na língua-I é abrupta e catastrófica por configurar-se como uma alteração no valor do parâmetro de uma geração a outra.

Em nossa pesquisa lidamos com uma área da sintaxe do PB que passou pelo processo de mudança linguística no âmbito da língua-I no século XIX, acarretando uma alteração no valor dos parâmetros da língua-I enquanto gramática nuclear dessa geração de falantes. Contudo, essa área da sintaxe se manteve no PB enquanto manifestação social, portanto, no âmbito da língua-E. A partir desse quadro, objetivamos verificar a atuação da mudança linguística na língua-E em relação às gramáticas coexistentes do PB entre as diferentes gerações de falantes; qual seria a atuação do nível de escolaridade nesse processo; e se haveria um reflexo disso na gramática não nativa do espanhol.

\section{AnÁlise}

\subsection{A intuição das gramáticas do $P B$}

A análise da intuição nas gramáticas do $\mathrm{PB}$ nos permitiu observar uma assimetria entre os informantes da geração mais jovem e os da geração com maior idade. Assim, os falantes brasileiros mais jovens apresentaram um 
índice mais elevado de aceitabilidade do objeto nulo e do pronome tônico, formas pertencentes à gramática adquirida do $\mathrm{PB}$, enquanto os falantes da outra geração apresentaram índices mais elevados de aceitabilidade do clítico, em detrimento do objeto nulo e do pronome tônico.

A partir desses resultados, constatamos que a coexistência de gramáticas no PB se manifesta de forma assimétrica entre as duas gerações de falantes. Essa assimetria seria decorrente do processo de escolarização $0^{20}$ dessas gerações. No caso dos informantes que têm a partir de 50 anos, a aprendizagem do português na escola foi permeada apenas pela abordagem da gramática normativa, em que o clítico de $3^{\mathrm{a}}$ pessoa consistia a única forma pronominal para a expressão do objeto acusativo e se prescreviam as formas de colocação pronominal que haviam sido excluídas da gramática de aquisição natural pela mudança linguística. No caso dos falantes da geração mais jovem, já se aborda a variação linguística, de modo que o pronome lexical é considerado como uma possibilidade da língua para a expressão do objeto acusativo, vinculada à variedade coloquial do $\mathrm{PB}$, enquanto o clítico seria abordado relacionado à variedade culta. Quanto às formas de colocação pronominal, já se considera a próclise ao principal como uma forma legítima do $\mathrm{PB}$, porém relacionada também à variedade coloquial.

Conforme Lucchesi (200I), nas últimas décadas do século XX a vulgarização do ensino e os meios de comunicação de massa teriam contribuído para

20 Com o objetivo de verificar a atuação da aprendizagem do português na escola na intuição do PB, analisamos livros didáticos correspondentes ao período de escolarização das faixas etárias estudadas. No caso da geração a partir dos 50 anos, que teria iniciado o processo de escolarização a partir dos anos 6o, analisamos o Manual de Gramática do Português (Cunha, I962). Quanto à geração que tem entre I2 e I8 anos, analisamos Português: uma proposta para o letramento (Soares, 2002) e Português: Linguagens (Cereja \& Magalhães, 2003), ambos utilizados na rede pública de ensino de São Paulo. 
A SINTAXE DO ESPANHOL E DO PORTUGUÊS BRASILEIRO

ADRIANA MARTINS SIMÕES

consolidar um afrouxamento da norma, nos termos do autor. Para Mattos e Silva (2004), a situação linguística atual do Brasil é um reflexo do processo histórico do país, processo esse que ocasionou uma desigualdade linguística entre as gerações jovens da atualidade e as gerações anteriores, cujo ensino pautou-se pela norma idealizada. Além dos fatores históricos, outro fator que contribuiria com essa desigualdade, segundo Mattos e Silva (2004), seria a massificação do ensino não acompanhada de sua qualidade. Assim, as diferenças linguísticas entre as duas gerações que analisamos têm origem tanto no processo histórico do país quanto na precarização do ensino. No processo de escolarização da geração mais jovem, a menor pressão da gramática normativa e a abordagem da variação linguística teriam conduzido a uma menor consolidação do clítico e a uma maior aceitação das formas que integram a gramática adquirida do PB.

Embora a mudança na língua- ${ }^{21}$ tenha ocorrido no século XIX e tenha excluído o clítico e a próclise ao auxiliar da gramática adquirida do PB, essas formas se mantiveram na língua por intermédio da aprendizagem formal escolar, como manifestação social. Com base nisso, a assimetria na coexistência de gramáticas no PB na intuição das duas gerações de falantes reflete o processo gradual de mudança linguística no âmbito da língua-E proposto por Lightfoot (2006). Portanto, a mudança linguística a que nos referimos ocorre no âmbito da gramática que é produto social, ainda que se relacione também com a gramática enquanto fenômeno biológico ${ }^{22}$, e seria consequência de uma mudança no processo escolar.

2I Nesse caso nos referimos à língua-I enquanto gramática nuclear, resultado de fixação paramétrica, sem considerar a periferia marcada.

22 Esclarecemos que na medida em que o clítico e a próclise ao auxiliar permanecem na gramática do PB como resquícios da mudança linguística processada no século XIX, tendo como base a perspectiva 


\subsection{A intuição na gramática não nativa do espanhol: reflexo do $P B$ e reestruturação}

Constatamos que a coexistência de gramáticas que ocorre no PB e sua assimetria entre as duas gerações de falantes se reflete na gramática não nativa do espanhol. Assim, observamos indícios de que a intuição dos aprendizes da geração mais jovem seria mais permeável à gramática adquirida do PB na medida em que o objeto nulo e o pronome tônico apresentaram os índices mais elevados de aceitabilidade. Por outro lado, a intuição da outra geração de aprendizes apresentou os índices mais elevados de aceitabilidade do clítico, sobretudo os aprendizes com o $\mathrm{ES}^{23}$. Esses resultados confirmaram nossa hipótese de que a geração da FEI teria sua gramática não nativa mais permeável à gramática adquirida do PB. Além disso, o fato de serem os aprendizes da FE2 os que apresentaram o índice mais elevado de aceitabilidade do clítico tanto na intuição no PB quanto na gramática não nativa evidencia que, parte do que parece ser um reflexo da gramática do espanhol na gramática não nativa, seria, na realidade, o reflexo do PB aprendido, que se apresenta mais consolidado na gramática dos falantes dessa geração.

Por outro lado, na intuição dos aprendizes dos níveis mais avançados de aprendizagem do espanhol, observamos que tende a diminuir o índice de aceitabilidade do objeto nulo, do pronome lexical e da próclise ao principal,

gerativa Chomsky (I981, I986), consideramos que essas formas do PB se incorporam à periferia marcada e integram, portanto, a língua-I. Considerar essas formas também como língua-E não excluiria essa outra visão.

23 Em relação ao pronome lexical, apesar de apresentar baixo índice de aceitabilidade tanto na intuição do PB quanto na intuição não nativa dessa geração, seu índice de aceitabilidade se apresenta mais elevado na intuição não nativa do que na intuição do PB do grupo com o ES. Isso revela que, embora internalizado na gramática adquirida do $\mathrm{PB}$, devido à sua estigmatização social e à pressão da gramática normativa no processo de escolarização, essa geração apresenta pouca aceitação desse pronome na intuição da LM. Por outro lado, esse pronome se reflete de forma mais livre na intuição não nativa. 
A SINTAXE DO ESPANHOL E DO PORTUGUÊS BRASILEIRO

ADRIANA MARTINS SIMÕES

formas que compreendem a gramática adquirida do $\mathrm{PB}$, bem como observamos uma tendência a aumentar o índice de aceitabilidade das formas que compreendem a gramática do espanhol, sendo estas o clítico, a próclise ao auxiliar e a ênclise ao principal. Esses resultados constituem evidências de reestruturação da gramática não nativa do espanhol (Liceras, I996, I997, 2002, 2003) conforme o aprendiz é exposto por mais tempo ao input e às regras formais dessa língua.

Assim, há indícios tanto do reflexo das gramáticas do PB quanto da gramática do espanhol na gramática não nativa desses aprendizes. Entretanto, poderíamos delimitar em que momentos se trata do reflexo das gramáticas do PB ou do espanhol na intuição não nativa?

Os dados mostraram que as formas pertencentes à gramática adquirida do PB se concentraram na intuição dos aprendizes do nível inicial de aprendizagem. Isso revela o reflexo da gramática do PB na gramática não nativa dos aprendizes.

Em contrapartida, verificamos a ocorrência de índices elevados de aceitabilidade da próclise ao auxiliar com o pronome de $\mathrm{I}^{\mathrm{a}}$ pessoa, que corresponde apenas à gramática do espanhol, na intuição dos aprendizes do nível básico de aprendizagem. Desse modo, tendo em vista que esse pronome possui uma forma fonética, constitui uma categoria morfológica e desempenha uma função sintática poderia ser considerado um elemento desencadeador de reestruturação da gramática não nativa ${ }^{24}$ (Liceras, I997, 2002, 2003) que atuaria desde o momento inicial de aquisição/aprendizagem do espanhol.

Observamos também que a próclise ao auxiliar e a ênclise ao principal com o clítico de $3^{\mathrm{a}}$ pessoa, correspondentes às gramáticas de ambas as

24 Na pesquisa de Yokota (2007) o clítico neutro foi a forma preferida de realização do objeto oracional tanto na produção oral como escrita dos aprendizes brasileiros. Com base nesse resultado, a autora propôs que o clítico neutro atuaria como um desencadeador de reestruturação da gramática não nativa. 
línguas, apresentaram os índices mais elevados de aceitabilidade na gramática não nativa em detrimento das formas de colocação pronominal que correspondem apenas a uma das duas línguas. Com base nesse resultado, propomos que quando há uma coincidência entre as gramáticas da LM e da língua alvo, ambas as gramáticas atuariam desde o momento inicial de aprendizagem e a coincidência de gramáticas poderia acelerar o processo de reestruturação.

Detectamos que, apesar de os dados mostrarem que conforme aumenta o nível de aprendizagem do espanhol a intuição não nativa dos aprendizes tende a apresentar índices mais elevados de aceitabilidade do clítico e um decréscimo no índice de aceitabilidade do objeto nulo, os aprendizes não apresentaram aceitação categórica do clítico com antecedente [+específico; +definido] e o objeto nulo continua sendo aceito em referência a esse tipo de antecedente, ao contrário do que esperaríamos na intuição de falantes nativos do espanhol. Interpretamos esses resultados como um indício de que a representação mental dos aprendizes não corresponderia à de um falante nativo. Isso seria decorrente de que os aprendizes de LE não captariam as propriedades abstratas da língua alvo que desencadeiam a fixação de parâmetros, como ocorre na aquisição da LM (Liceras, 1996, I997, 2002, 2003). Relacionamos também esses resultados ao fenômeno de supergeneralização de regras observado por González (I994, I998, I999, 200I, 2003, 2005), que a levou a propor que não haveria assimilação das regras subjacentes da LE pelo aprendiz, o que revelaria que aprendizagem não significa aquisição.

Essas evidências de que a representação mental dos aprendizes de LE não seria como a dos falantes nativos nos levaram à conclusão de que há diferenças paramétricas entre o espanhol e o português brasileiro nas diferentes possibilidades de realização plena ou nula do objeto pronominal acusativo. Assim, o aprendiz de LE já não seria sensível aos traços abstratos e devido a 
A SINTAXE DO ESPANHOL E DO PORTUGUÊS BRASILEIRO

ADRIANA MARTINS SIMÕES

isso já não seria capaz de perceber em que contextos semânticos o clítico seria categórico ou o objeto nulo seria possível no espanhol, questão que estamos aprofundando em nossa pesquisa atual.

Obtivemos indícios também de que, ao contrário do que ocorre na aquisição da LM, na aquisição de LE, quando se adquire/aprende uma determinada propriedade relacionada a um único parâmetro, as demais propriedades não seriam adquiridas em conjunto. Nossa evidência a respeito consiste no fato de que a aquisição do clítico não parece estar relacionada à da próclise ao auxiliar com o pronome de $\mathrm{I}^{\mathrm{a}}$ pessoa, já que na intuição dos aprendizes do nível avançado de aprendizagem de espanhol o índice de aceitabilidade do clítico apresenta-se muito mais elevado do que o índice referente a essa forma de colocação. Entretanto, se se focaliza o reflexo da LM na gramática não nativa, ocorreria uma reação em cadeia na produção dos aprendizes, como constatou González (1994, 1998, I999, 200I, 2003, 2005), reação esta que se assemelha à aquisição da LM, em oposição ao processo de reestruturação.

\subsection{Reflexões sobre o estatuto da gramática não nativa do espanhol e o} fenômeno da permeabilidade

Com base na proposta de Kato (2005) de que haveria uma coexistência de gramáticas no PB de falantes letrados ${ }^{25} \mathrm{e}$ tendo em vista as evidências sobre a intuição não nativa do espanhol, propomos que a gramática não nativa compreenderia outra gramática, que poderíamos denominar de $\mathrm{G}^{26}$. Assim,

25 Conforme Kato (2005), os brasileiros letrados teriam uma gramática decorrente da fixação de parâmetros, a qual denomina de Gi, e uma gramática decorrente de aprendizagem escolar, que denomina de G2. A autora propõe que a gramática que se origina de aprendizagem formal equivaleria à aprendizagem de um LE.

26 Outras línguas estrangeiras adquiridas/aprendidas não estão sendo consideradas nesse caso. 
consideramos que, da mesma forma que a gramática aprendida do PB seria uma expansão da língua-I, quando o aprendiz adquire uma LE, haveria a expansão da língua-I e esse processo originaria uma gramática não nativa, que também teria o estatuto de periferia marcada.

Assim como a gramática aprendida do PB permaneceria ligada à adquirida, a gramática não nativa se ligaria às gramáticas da LM. Isso nos leva a interpretar o fenômeno da permeabilidade da gramática não nativa à(s) gramática(s) da LM como uma consequência dessa ligação. Portanto, além de se originar da não (re)fixação de parâmetros, conforme propõe Liceras (I996, 1997, 2002, 2003), a permeabilidade poderia também ser devida ao fato de que as gramáticas se mantenham ligadas.

Uma evidência empírica a respeito dessa ligação, que demonstraria que a gramática não nativa operaria tanto com a gramática da LE quanto com as gramáticas da LM, seria o fato de que quando uma construção corresponde a ambas gramáticas, como é o caso da ênclise ao principal com o pronome de $3^{\mathrm{a}}$ pessoa, o índice de aceitabilidade apresentou-se mais elevado na gramática não nativa do que quando determinada construção corresponde apenas à gramática do espanhol.

\section{CONSIDERAÇÕES FINAIS}

Os resultados de nossa análise evidenciaram que a coexistência de gramáticas do PB se apresenta assimétrica entre as duas gerações de falantes e passa por um processo gradual de mudança linguística no âmbito da língua-E. Assim, a intuição dos falantes da geração mais jovem apresenta maior aceitabilidade das formas correspondes à gramática adquirida do $\mathrm{PB}$, enquanto a outra geração apresenta índices mais elevados de aceitabilidade da gramática aprendida do 
A SINTAXE DO ESPANHOL E DO PORTUGUÊS BRASILEIRO

ADRIANA MARTINS SIMÕES

$\mathrm{PB}$, que se vincula à aprendizagem formal. Constatamos que essa assimetria entre as duas gerações na intuição do PB se manifesta na intuição não nativa, o que confirmou nossa hipótese de que a gramática não nativa da geração mais jovem seria mais permeável à gramática contemporânea do PB. Por outro lado, parte do que parecia ser um reflexo da gramática do espanhol na gramática não nativa dos aprendizes de maior faixa etária, seria, na realidade, o reflexo do PB aprendido. Além do reflexo da gramática da LM na intuição não nativa, obtivemos indícios de reestruturação da gramática não nativa e de que elementos visíveis poderiam desencadear esse processo. Entretanto, há indícios de que apesar de haver reestruturação, a representação da gramática não nativa não corresponderia a de um falante nativo, devido ao fato de este não ser capaz de captar as propriedades abstratas da língua alvo, que conduzem à fixação de parâmetros. Além disso, o processo de reestruturação seria apenas parcial, na medida em que as propriedades relacionadas a um mesmo parâmetro não seriam adquiridas em conjunto. As evidências a respeito da gramática não nativa que encontramos nos levaram a propor com base em Kato (2005) que a gramática não nativa teria o mesmo estatuto da gramática aprendida do PB e que a permeabilidade poderia ser decorrente da ligação entre todas as gramáticas.

\section{REFERÊNCIAS BIBLIOGRÁFICAS}

Campos, Hector. "Indefinite object drop". In: Linguistic Inquiry, I7, I986, 354-359.

Cereja, William; Magalhães, Thereza. Português: Linguagens. $1^{\circ}$ ao $3^{\circ}$ ano do Ensino Médio. São Paulo: Atual Editora, 2003.

Chomsky, Noam. Lectures on Governing and Binding. Dordrecht: Foris, I98I. 
CARACOL 4 / DOSSIÊ

Knowledge of Language: its nature, origin and use. New York: Praeger, I986.

Cunha, Celso. Manual de Português: primeira e segunda séries ginasiais. Rio de Janeiro: São José, I962.

Cyrino, Sonia Maria Lazzarini. "Observações sobre a mudança diacrônica no português do Brasil: objeto nulo e clíticos". In Roberts, Ian; Kato, Mary (orgs.). Português brasileiro: uma viagem diacrônica. Campinas - SP: Editora da Unicamp, I993, I63-184.

"O objeto nulo do português brasileiro". In: DELTA, I2:2, I996, 22I-238.

Demonte, Violeta. "Las categorías vacías". In: Teoría sintáctica: De las estructuras a la rección. Madrid: Síntesis, I994, I97-217.

Di Tullio, Ángela. Manual de gramática del español. Buenos Aires: Edicial, I997.

Duarte, Maria Eugenia Lamoglia. "Clítico acusativo, pronome lexical e categoria vazia no português do Brasil". In: Tarallo, Fernando (org.). Fotografias Sociolingüísticas. Campinas - SP. Pontes: Editora da Unicamp, I989, I9-34.

Fanjul, Adrián Pablo. "Espacio de la persona en la versión portugués-español: un problema de identidad discursiva”. In: Estudos Acadêmicos UNIBERO, ıо, jul - dez, I999, I35-I54.

Fernández-Ordóñez, Inés. "Leísmo, laísmo y loísmo". In: Bosque, Ignacio; Demonte, Violeta (orgs.). Gramática Descriptiva de la Lengua Española. Madrid: Espasa, I999, I3I7-I39I.

Fernández Soriano, Olga. "El pronombre personal. Formas y distribuciones. Pronombres átonos y tónicos”. In: Bosque, Ignacio; Demonte, Violeta (orgs.). Gramática Descriptiva de la Lengua Española. Madrid: Espasa, I999, I209-I273.

Galves, Charlotte. "O enfraquecimento da concordância no português brasileiro". In: Roberts, Ian; Kato, Mary (orgs.). Português brasileiro: uma viagem diacrônica. Campinas - SP: Editora da Unicamp, I993, 387-408. 
A SINTAXE DO ESPANHOL E DO PORTUGUÊS BRASILEIRO

ADRIANA MARTINS SIMÕES

Ensaios sobre as gramáticas do português. Campinas - SP: Editora da Unicamp, 200I.

González, Neide Therezinha Maia. Cadê o pronome? O gato comeu. Os pronomes pessoais na aquisição/aprendizagem do espanhol por brasileiros adultos. Tese de doutorado. DL/FFLCH/USP, São Paulo: I994, inédita.

"Pero ¿qué gramática es ésta? Los sujetos pronominales y los clíticos en la interlengua de brasileños adultos aprendices de Español/LE”. In: RILCE: Español como lengua extranjera: investigación $\gamma$ docencia, Pamplona, Universidad de Navarra, I4.2, I998, 243-263.

"Sobre a aquisição de clíticos do espanhol por falantes nativos do português". In: Cadernos de Estudos Lingüísticos, Campinas: UNICAMP/IEL, 36, I999, 163-176.

"La expresión de la persona en la producción de español lengua extranjera de estudiantes brasileños: perspectivas de análisis”. In: Trouche, A. L. G.; Reis, L. F. (orgs.). Hispanismo 2000. v. I. Brasília: Ministerio de Educación, Cultura y Deporte/ABH, 200I, 239-256.

"Lugares de interpretação do fenômeno da aquisição de línguas estrangeiras”. In: Estudos Lingüísticos, XXXIII, Campinas (SP), UNICAMP, 2003 .

"Quantas caras tem a transferência? Os clíticos no processo de aquisição/ aprendizagem do Espanhol/Língua Estrangeira”. In: Bruno, Fátima Cabral (org.). Ensino-Aprendizagem de Línguas Estrangeiras: reflexão e prática. S. Carlos (SP): Claraluz, 2005, 53-70.

"Portugués brasileño y español: lenguas inversamente asimétricas". In: Celada, María Teresa; González, Neide Therezinha Maia (orgs.). Gestos trazan distinciones entre la lengua española y el portugués brasileño. SIGNOS ELE, diciembre, 2008. http://www.salvador.edu.ar/signosele/ 
CARACOL 4 / DOSSIÊ

Groppi, Mirta. Pronomes pessoais no português do Brasil e no espanhol do Uruguai. Tese de Doutorado. FFLCH-USP, São Paulo: 1997.

Kato, Mary. "The distribution of pronouns and null elements in object position in Brazilian Portuguese". In: Ashby, W. et al. (orgs.). Linguistics Perspectives on the Romance Languages: Selected Papers from the XXI Linguistic Symposium on romance Languages. Amsterdam \& Philadelphia: John Benjamins, I993, 225-235.

"Pronomes fortes e fracos na sintaxe do Português Brasileiro". In: Revista Portuguesa de Filologia, Coimbra, Portugal, XX, 2002, IOI-I22.

"A gramática do letrado: questões para a teoria gramatical". In: Marques, M. A. et al. (orgs.). Ciências da Linguagem: trinta anos de investigação e ensino. Braga: CEHUM (U. do Minho), 2005, I3I-I45.

Kato, Mary; Tarallo, Fernando. "Anything YOU can do in Brazilian Portuguese". In: Jaeggli, O.; Silva-Corvalán, C. (orgs.). Studies in Romance Linguistics. Dordrecht: Foris, I986.

Labov, William. Padrões Sociolinguísticos. Trad. de Marcos Bagno, Marta Pereira Scherre, Carolina R. Cardoso. São Paulo: Parábola, 2006.

Laca, Brenda. "Presencia y ausencia de determinante". In: Bosque, Ignacio; Demonte, Violeta (orgs.). Gramática Descriptiva de la Lengua Española. Madrid: Espasa, 1999, 891-928.

Liceras, Juana Muñoz. La adquisición de las lenguas segundas y la gramática universal. Madrid: Síntesis, 1996.

"The now and then of L2 growing pains. Views on the acquisition and use of a second language". In: EUROSLA '97. Proceedings, Barcelona, Universitat Pompeu Fabra., I997, 65-85.

“Spanish Li/L2 crossroads: can we get there from here?”. In: Pérez-Leroux, A. T. et al. (orgs.). Romance linguistics: Theory and acquisition. Amsterdam: John Benjamins, 2002, 3I7-350. 
A SINTAXE DO ESPANHOL E DO PORTUGUÊS BRASILEIRO

ADRIANA MARTINS SIMÕES

"Monosyllabic place-holders in early child language and the LI/L2 'Fundamental Difference Hypothesis'”. In: Kempchinsky, P. et al. (orgs.). Theory, practice and acquisition. Papers from the $6^{\text {th }}$ Hispanic Linguistics Symposium and the $5^{\text {th }}$ Conference on the Acquisition of Spanish and Portuguese. Somerville, Mass.: Cascadilla Press, 2003, 258-283.

Lightfoot, David. How New Languages Emerge. Cambridge University Press, 2006.

Lucchesi, Dante. "As duas grandes vertentes da história sociolinguística do Brasil (I500-2000)”. In: DELTA, I7:I, 200I, 97-I30.

Magalhães, Telma. O sistema pronominal sujeito e objeto na aquisição do Português Europeu e do Português Brasileiro. Tese de Doutorado. IEL/Unicamp, São Paulo: 2006.

Mattos e Silva, Rosa Virgínia. O português são dois. São Paulo: Parábola, 2004.

Nazzi, T.; Bertoncini, J.; Mehler, J. "Language discrimination by newborns: toward an understanding of the role of rhythm". In: Journal of experimental psychology: human perception and performance, 24, $\mathrm{n}^{\circ}$ 3, 1998, 756-766.

Nunes, Jairo Morais. "Direção de cliticização, objeto nulo e pronome tônico na posição de objeto em português brasileiro". In: Roberts, Ian; Kato, Mary (orgs.). Português Brasileiro. Uma viagem Diacrônica. Campinas - SP: Editora da Unicamp, I993, 207-222.

Pagotto, Emilio Gozze. "Clíticos, mudança e seleção natural". In: Roberts, Ian; Kato, Mary (orgs.). Português Brasileiro. Uma viagem Diacrônica. Campinas SP: Editora da Unicamp, I993, I85-206.

Simões, Adriana Martins. Preenchimento do objeto direto pronominal de terceira pessoa no espanhol, no português brasileiro e na produção não-nativa em espanhol de falantes do PB. Trabalho de Graduação Individual. Área de Língua Espanhola 
CARACOL 4 / DOSSIÊ

e Literaturas Espanhola e Hispano-Americana. DLM/FFLCH/USP, São Paulo: 2006.

Clítico, objeto nulo ou pronome tônico? Quanto e como a variação/mudança no paradigma do preenchimento pronominal do objeto acusativo de $3^{\mathrm{a}}$ pessoa no português brasileiro se reflete na aquisição/aprendizagem do espanhol pelos aprendizes brasileiros ao longo das gerações. Dissertação de Mestrado. DLM/FFLCH/USP, São Paulo: 20IO. http://www.teses.usp.br/teses/disponiveis/8/8I45/tdeI6II20IO-I64450/pt-br.php

Soares, Magda. Português: Uma proposta para o letramento. São Paulo: Moderna, 2002.

Tarallo, Fernando. "Diagnosticando uma gramática brasileira: o português d'aquém e d'além mar ao final do século XIX". In: Roberts, Ian; Kato, Mary (orgs.). Português Brasileiro. Uma viagem Diacrônica. Campinas - SP: Editora da Unicamp, I993, 69-105.

Weinreich, Uriel; Labov, William; Herzog, Marwin. Fundamentos empíricos para uma teoria da mudança lingüística. Trad. de Marcos Bagno. São Paulo: Parábola Editorial, 2006.

Werker, J. F.; Tees, R. C. "Influences on infant speech processing: toward a new synthesis". In: Annual Review of psychologist, I999.

Yokota, Rosa. O que eu falo não se escreve. E o que eu escrevo alguém fala? A variabilidade no uso do objeto direto anafórico na produção oral e escrita de aprendizes brasileiros de espanhol. Tese de Doutorado. DLM/FFLCH/USP, São Paulo: 2007. http://www.teses.usp.br/teses/disponiveis/8/8I45/tde-o6II2007-II4658/ 